American Journal of Environmental Sciences 8 (3): 241-247, 2012

ISSN 1553-345X

(C) 2012 Science Publications

\title{
The Water Demand Management by Monitoring the Technology Performance and the Water Use Efficiency
}

\author{
Fraj Chemak \\ Departement of Rural Economics, \\ National Institute for Agricultural Research of Tunis, University of Carthage, Tunisia
}

\begin{abstract}
Problem statement: Given the climate constraints and the limited resources, Tunisia has developed the irrigated sector in order to diversify the agricultural production and to meet the food needs of the population. Today the policy of water supply reaches its limits and the efforts should be turned to the management of the water demand. Within this context, this research aims to analyze the farming system, the technology performance and the water use efficiency of the irrigated farms in the Sidi Bouzid region. Approach: By monitoring the sample of 47 farms during the harvesting years 2007, 2008 and 2009 we have gathered database which involved technical and economical details. By analyzing the farming system we have identified the technology process in order to estimate the production frontier using the Data Envelopment Analysis (DEA) approach. The sub-vector approach of the DEA model was used to compute the water use efficiency. Results: The empirical findings showed that farmers grow olive trees, cereal crops, forage crops and horticulture crops. During the surveyed period the share of the different crops did not change significantly. The water consumption reaches only an average of $2700 \mathrm{~m}^{3} / \mathrm{ha}$. However, the charge of irrigation represents more than $40 \%$ out of the total expenditures. The results of the DEA model showed that $50 \%$ of farms are inefficient and the technical efficiency reaches an average of $81 \%$. The average of the scale efficiency reached $88 \%$. However, the water use efficiency did not exceed an average of $68 \%$. Hence, $32 \%$ of the water currently used should be saved. Conclusion: There is a wide gap to improve skills and the ability of the farmers to achieve the best of the water use efficiency. Thus, we suggest that the state intervention is necessary not only to reduce the wasting of water but also to set up an accompanying device that reconciles water conservation and the production targets.
\end{abstract}

Key words: Irrigated areas, technical efficiency, water use efficiency, Data Envelopment Analysis (DEA), production targets

\section{INTRODUCTION}

The Tunisian agricultural activity remains one of the dominant economical sectors of the country. In fact, the sector contributes up to $13 \%$ of the GDP and employs $16 \%$ of the active population. Given the climate constraints (mainly semi-arid) and the limited resources, the development of the agriculture has been stimulated by the development of the irrigated sector. In 2007, the irrigated areas reached 433000 ha of which 229000 ha were arranged in Irrigated Public Areas (IPBAs). In such areas, farmers share a common resource according to a collectively organized scheme. The rest, called Irrigated Private Areas (IPRAs), use surface wells as private resources. The total irrigated area accounts for only $8 \%$ of the total agricultural land, but it contributes up to $35 \%$ of the national agricultural production. However, the government planes to improve this contribution in order to reach $50 \%$. The expansion of the irrigated sector has been achieved thanks to huge government efforts in terms of water harvesting and hydraulic infrastructure improvements.

Today the rate of the water mobilization is more than $90 \%$. Therefore, this policy of water supply reaches its limits and the efforts should be turned to the management of the water demand. Over the past two decades, the government has implemented different programs in order to reduce the losses and to control the water demand. In fact, since 1990, a new tariff policy has been implemented. Each year the price of water has been increased by $15 \%$ in nominal value $(9 \%$ in real value) in order to improve managing cost recovery and to encourage farmers to minimize water wasting. Also, since 1990 the management of IPBAs has been transferred to the users through the creation of "Collective Interest Groups" (CIGs) which is a farmer's association having the responsibility of selling and managing water distribution. In 2007, 1081 CIGs were 
created to manage $80 \%$ of the irrigated public areas Ministry of Agriculture, 2008b. In 1995, the government launched the "National program of water conservation" which aims to minimize the losses of water at the field level. This program allows farms that introduce water saving irrigation systems (sprinklers, drip irrigation) to benefit from investment subsidies which varies between 40 and $60 \%$ of its cost according to the investment category.

However, these programs do not lead to significant changes in the irrigation practices (Chraga and Chemak, 2003; Hemdane, 2002). Indeed, these programs did not focus on the assessment of the technology processes. Hence, their current implementation did not involve the best of water productivity and the best of water conservation. One weakness of the Tunisian water policies undertaken until now is that they did not take into account the motivations and practices of farmers. These practices involve the farming system, the kind of access to the water resource and the intrinsic operational conditions of households (Capital, Skills, livelihoods constraints, futures purposes...).

For a long time the literature on water use efficiency was mainly based on engineering and agronomic concepts. Depending on the aspects one wishes to emphasize, Shideed (2005) explained that this concept had been defined in various ways by hydrologists, physiologists and agronomists. For example, agronomists are interested in water use efficiency as the ratio of the amount of water actually used by the crop to the water quantity applied to the crop (Omezzine and Zaibet, 1998). However, these various definitions did not encompass water as an economic good and did not allow one to assess the economical level of water use efficiency. Thus the economic approach of water use efficiency focuses the analysis on the whole production technology process. Therefore, water consumption was used in combination with a whole set of other inputs, such as land, fertilizers, labor. Also, it was assessed according to the production frontier which represents an optimal allowance of the inputs. This economic approach aims to assess the grower's managerial capability to implement technology processes (Karagiannis et al., 2003).

In order to tackle these issues, this research aims to analyze the farming system, the technology performance and the water use efficiency of the irrigated farms in the Sidi Bouzid region. The remainder of this study is structured as follows. The second section presents the theoretical framework and our approach to collect data. The third section presents the empirical model and the discussion of the obtained results. The last section concludes with a formulation of some policy recommendations.

\section{MATERIALS AND METHODS}

Theoretical framework: DEA approach: Since the pioneer study of Farrell (1957), the concept of efficiency has been widely used by many authors interested in assessing the global productivity of the Decision Making Unit (DMU) such as a firm or a public sector agency (Rayeni and Saljoofhi, 2010; Farzianpour et al., 2012; Zreika and Elkanj, 2011). As a result, empirical studies based on his approach have been multiplied, putting forward the relevance of the concept (Emrouznejad et al., 2008; Gorton and Davidova, 2004; Odeck, 2009; Wang, 2010).

In fact, let consider the DMUs which produce the output $\mathrm{Y}$ using two inputs $\mathrm{X}_{1}$ and $\mathrm{X}_{2}$. As Farrell had shown, the DMU A (Fig. 1) which uses $X_{1}^{\mathrm{A}}$ and $\mathrm{X}_{2}^{\mathrm{A}}$ quantities of $\mathrm{X}_{1}$ and $\mathrm{X}_{2}$ respectively may produce the same quantity of the output using only $\mathrm{X}_{1}^{\mathrm{B}}$ and $\mathrm{X}_{2}^{\mathrm{B}}$ quantities of $X_{1}$ and $X_{2}$ respectively. Hence, the DMU $A$ is inefficient and its index of Technical Efficiency $\left(\mathrm{TE}_{\mathrm{A}}\right)$ is measured by the following ratio: $\mathrm{TE}_{\mathrm{A}}=\frac{\mathrm{OB}}{\mathrm{OA}}$

In order to measure this technical efficiency, several studies have applied Data Envelopment Analysis (DEA) due to its advantages. Using the linear programming, the DEA model remains the sole approach to assess the multi-inputs/multi-ouputs technologies without any restriction on the functional form (Cook and Seiford, 2009). Until 1984, the DEA approach was based on the Constant Returns to Scale (CRS) assumption (Charnes et al., 1978). Banker et al. (1984) investigated returns to scale and proposed the DEA model under Variable Returns to Scale. This model allows us to compute the pure technical efficiency which cannot be less than the value of technical efficiency obtained under CRS. Knowing the CRS and the VRS scores one can assess the Scale Efficiency (SE) which measures the impact of scale size on the productivity of the DMU. It is defined as follows:

$$
\mathrm{SE}=\frac{\text { Technicalefficiencyunder CRS }}{\text { Technicalefficiencyunder VRS }}
$$

Let us consider $\mathrm{N}$ DMUs that produce the output vector $\mathrm{Y}\left(\mathrm{y}_{1}, \ldots, \mathrm{y}_{\mathrm{s}}\right)$ using the input vector $\mathrm{X}\left(\mathrm{x}_{1}, \ldots, \mathrm{x}_{\mathrm{m}}\right)$. To compute the technical efficiency of DMU $\mathrm{j}_{0}$ under the VRS assumption we have to solve the following linear program (Input oriented model) Eq. 1: 


$$
\operatorname{Min}_{\left(\lambda, \mathrm{kos}^{-}, \mathrm{s}^{+}\right)}\left[\mathrm{k}_{\mathrm{o}}-\varepsilon\left(\sum_{\mathrm{i}=1}^{\mathrm{m}} \mathrm{S}_{\mathrm{i}}^{-}+\sum_{\mathrm{r}=1}^{\mathrm{s}} \mathrm{S}_{\mathrm{r}}^{+}\right)\right]
$$

Subject to:

$$
\begin{aligned}
& \sum_{j=1}^{N} \lambda_{j} x_{i j}=k_{o} x_{i j o}-S_{i}^{-} i=1, \ldots, m \\
& \sum_{j=1}^{N} \lambda_{j} y_{r j}=y_{r j o}+S_{r}^{+} r=1, \ldots . S \quad \sum_{j=1}^{N} \lambda_{j}=1
\end{aligned}
$$

$\lambda_{\mathrm{j}} \geq 0, \mathrm{j}=1, \ldots, \mathrm{N}, \mathrm{S}_{\mathrm{j}}^{-}, \mathrm{S}_{\mathrm{r}}^{+} \geq 0 \forall \mathrm{i}$ and $\mathrm{r}, \mathrm{k}_{0}$ free $\varepsilon$ is a non-Archimedean infinitesimal.

The optimal value $\mathrm{k}_{0}^{*}$ represents the technical efficiency of DMU $j_{0}$. Its value lies between 0 and 1 and indicates how much the DMU should be able to reduce the use of all inputs without decreasing its level of outputs with reference to the best performers or benchmarks. $S$ represents the slack variables introduced within the constraints to get a Pareto efficient bundle $(\mathrm{X}, \mathrm{Y})$. These slack variables represent the difference between the optimal values and the observed values of inputs and outputs at the optimal solution. The first constraint limits the proportional decrease in input, when $k$ is minimized, to the input use achieved with the best observed technology. The second constraint ensures that the output produced by the ith farm is smaller than that on the frontier. Both these constraints ensure that the optimal solution belongs to the production possibility set. The third constraint, called also convexity constraint, ensures the VRS assumption of the DEA model. Without this constraint the model treats the CRS specification of the DEA approach.

However, Fare et al. (1994) suggest the notion of sub-vector efficiency to deal with the technical efficiency use of each input variable. Hence, they proposed to solve the following linear program Eq. 2:

$$
\operatorname{Min}_{\left(\lambda, k_{o}, s\right)}\left[k_{o}^{v}-\varepsilon\left(S_{v}^{-}+\sum_{i=1}^{m-v} S_{i}^{-}+\sum_{r=1}^{s} S_{r}^{+}\right)\right]
$$

Subject to:

$$
\begin{aligned}
& \sum_{j=1}^{N} \lambda_{j} x_{j}^{v}=k_{o}^{v} x_{j o}^{v}-S_{v}^{-} \\
& \sum_{j=1}^{N} \lambda_{j} x_{i j}=x_{i j o}+S_{i}^{-} i=1, \ldots . m=v \\
& \sum_{j=1}^{N} \lambda_{j} y_{r j}=y_{r j o}+S_{r}^{+} r=1, \ldots . S \sum_{j=1}^{N}=1
\end{aligned}
$$

$\lambda_{\mathrm{j}} \geq 0, \mathrm{j}=1, \ldots, \mathrm{N}, \mathrm{S} \geq 0 \forall \mathrm{i}$ and $\mathrm{r}, \mathrm{k}_{0}^{\mathrm{v}}$ free $\varepsilon$ is a non-Archimedean infinitesimal.
Where, the optimal value of $\mathrm{k}_{0}^{v}$ measures the technical efficiency use of the $x^{v}$ revealed by the farm $j_{0}$. This is different from the technical efficiency $\mathrm{k}_{0}^{*}$ computed by solving the linear program (1). In fact if we get back to the Fig. 1, the technical efficiency regarding the use of the input $A_{1}^{x}$ is the ratio $\mathrm{TE}_{\mathrm{x}_{1}^{\mathrm{A}}}=\frac{O \mathrm{Ox}_{1}^{\mathrm{B}}}{\mathrm{Ox}_{1}^{\mathrm{A}}}$.

Hence, the optimal value of $\mathrm{K}_{0}^{v}$ should be analyzed as the water use efficiency if $\mathrm{x}^{\mathrm{v}}$ represents the variable of the water consumption.

Irrigated activity issues and data collection: Located in the Center of the country (Fig. 2), the region of Sidi Bouzid owes its economic and social development to irrigation. In fact, known as pastoral territory (semiarid) the region received an average of $250 \mathrm{~mm}$ of rainfall with important irregularity (Fig. 3). In order to encounter these constraints the government has invested in the irrigation development. Therefore the potential irrigable areas accounted for 40000 ha in 2007 which include 5500 ha of IPBAs. The irrigated sector generates up to $60 \%$ of the regional agricultural production Ministry of Agriculture, 2006 and contributes up to $16 \%$ of the national production of vegetables Ministry of Agriculture, 2008a. However, despite such development, significant difficulties remain in IPBAs as well as in IPRAs. Certain public irrigation channels have decayed resulting in significant water losses up to $40 \%$ Ministry of Agriculture, 1995. The use of the flood irrigation system is dominant leading to significant water losses. The proliferation of surface wells increases the overexploitation of the groundwater that is reflected in folding back and in increased salinity of water as well as soils. Each year, on average a folding back of approximately $30 \mathrm{~cm}$ was noted Ministry of Agriculture, 2006.

In order to investigate our research issues we analyze the irrigated farming system in the Western region of Sidi Bouzid (Fig. 2) which constitutes a representative region from an economical, institutional and social dynamics standpoint of the governorate, basically in terms of irrigation development (Abaab, 1999). Hence we have randomly selected 47 farms using the water public resource or/and the private resource for irrigation. We have carried out field surveys (plot by plot) in order to gather technical and economical data regarding the operational activities during the harvesting years 2007, 2008 and 2009. We have collected data relative to 82 plots of which 37 was irrigated by public water resources (IPBAs). The surveyed area reached an average of 220 ha of which 194 ha (88\%) ha were planted by olive trees. 


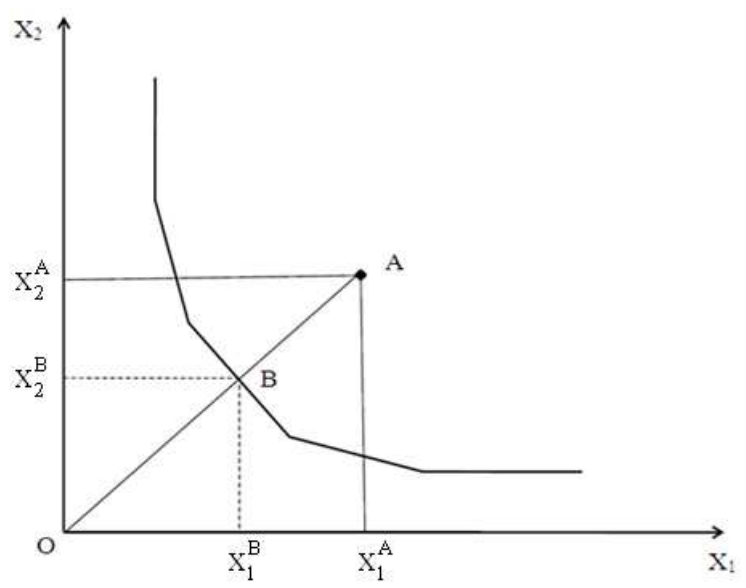

Fig. 1:Technical efficiency according to the input oriented model

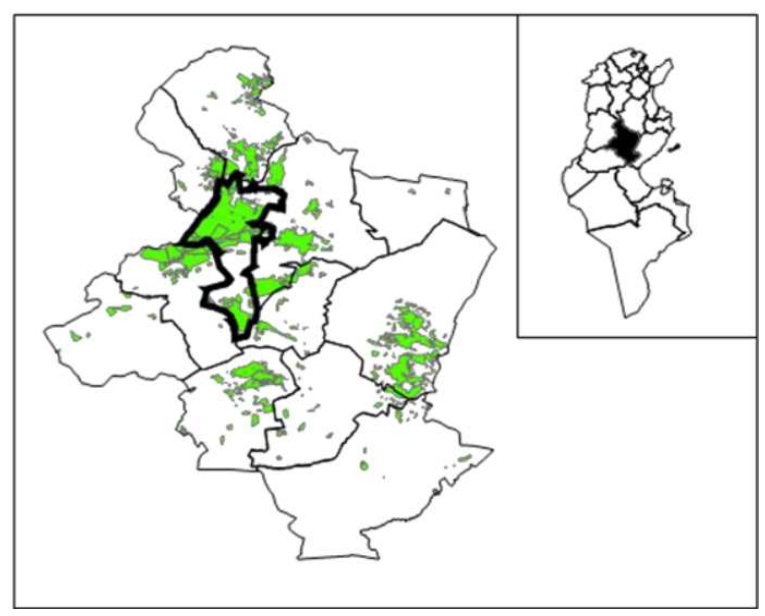

Fig. 2: Irrigable areas of the Sidi Bouzid region

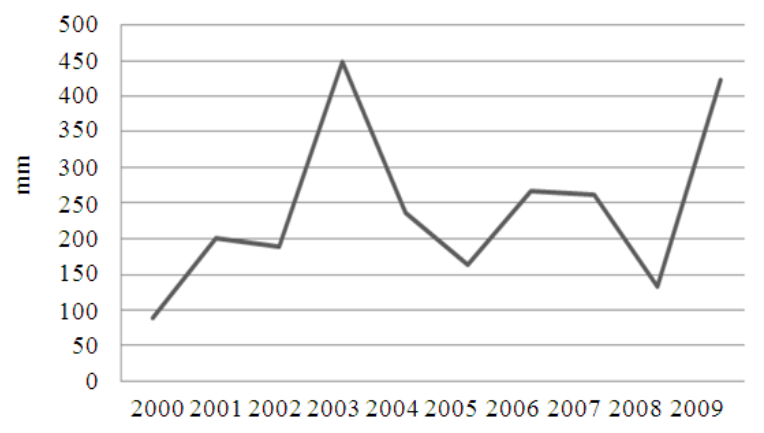

Fig. 3: Rainfall of the Sidi Bouzid region

\section{RESULTS}

Descriptive analysis: The irrigable area per farm reached an average of 4.7 ha. This potential area decreased to 1.6 ha in the IPBAs and 3.5 ha in the IPRAs. The average of the irrigated area per farm reached 6.2 ha leading to an intensification rate of the input land around $140 \%$ (Table 1). According to the water resource the irrigated area was 2.33 ha in the IPBAs and 4.64 ha in the IPRAs.

All farmers adopted floodwater as an irrigation system. Only few farmers have introduced a water saving system such, as sprinklers and drip irrigation, in order to irrigate some plots cultivated with horticulture crops. In 2009, 9 plots (20\%) in the IPRAs and 5 (13\%) in the IPBAs were irrigated using water saving system. The average of the water consumption per hectare (Table 2) was $2761 \mathrm{~m} 3 \mathrm{In}$ fact it reached $3043 \mathrm{~m}^{3} / \mathrm{ha}$ in the IPBAs against $2574 \mathrm{~m}^{3} / \mathrm{ha}$ in the IPRAs.

Regarding the revenue (Table 3), farmers earned an average of $993 \mathrm{TND} / \mathrm{ha}$. In 2008, this value has decreased by $18 \%$ while in 2007 as well as in 2009 has increased by $9 \%$. More than $55 \%$ of this revenue was ensured by the production of the olive trees. However, the average revenue of the crops production per hectare was two times the production of the olive trees. In fact the production value per hectare of the IPBAs reached an average of 1536 TND against 993 TND in the IPRAs. The average of the total charges per hectare was 680 TND. According to the water resource, the production costs were slightly higher in the IPRAs than in the IPBAs. This could be explained by the difference of the pumping price which reached an average of $0.224 \mathrm{TND} / \mathrm{m}^{3}$ in the IPRAs against $0.088 \mathrm{TND} / \mathrm{m}^{3}$ in the IPBAs. Furthermore, the average share of the irrigation charges represented $45 \%$ of the total charges. The mechanization, the fertilisation and the hired labor represented also for $42 \%$ of the total charges.

Technical efficiency and water use efficiency: Following the results of the descriptive analysis, we assume that the technology process may be represented by the following production function:

Oliv, Cult $=\mathrm{f}($ Land, Water, Mecan, Fertil and Lab)

Where:

Oliv = Revenue of the olive trees in TND

Cult = Revenue of the crops in TND

Land = Potential irrigable surface in hectares

Water $=$ Water consumption quantity in $\mathrm{m}^{3}$

Mecan $=$ Mechanization expenditures in TND

Fertil $=$ Fertilization expenditures in TND

$\mathrm{Lab}=$ Hired labor costs in TND 
Am. J. Environ. Sci., 8 (3): 241-247, 2012

Table 1: Dynamic of the cropping system (ha)

\begin{tabular}{|c|c|c|c|c|c|c|c|c|}
\hline & \multicolumn{2}{|l|}{2007} & \multicolumn{2}{|l|}{2008} & \multicolumn{2}{|l|}{2009} & \multicolumn{2}{|c|}{ Average } \\
\hline & Area & $\%$ & Area & $\%$ & Area & $\%$ & Area & $\%$ \\
\hline Olive Trees & 196.35 & 68 & 194.85 & 67 & 191.85 & 64 & 194.35 & 66 \\
\hline Cereal Crops & 20.75 & 7 & 26.75 & 9 & 32.15 & 11 & 26.56 & 9 \\
\hline Forage Crops & 29.55 & 10 & 23.97 & 8 & 32.54 & 11 & 28.68 & 10 \\
\hline Horticulture Crops & 44.05 & 15 & 45.90 & 16 & 44.50 & 14 & 44.81 & 15 \\
\hline Total Irrigated Areas & 290.70 & 100 & 291.52 & 100 & 301.04 & 100 & 294.42 & 100 \\
\hline Potential Irrigable Areas & 219.85 & & 220.85 & & 217.85 & & 219.51 & \\
\hline Land Intensification Rate & & 137 & & 137 & & 145 & & 140 \\
\hline
\end{tabular}

Table 2: Water consumption (m3/ha)

\begin{tabular}{lllll}
\hline & 2007 & 2008 & 2009 & Average \\
\hline IPBAs & 3530 & 2771 & 2829 & 3043 \\
IPRAs & 2682 & 2534 & 2507 & 2574 \\
Sample & 3007 & 2629 & 2647 & 2761 \\
\hline
\end{tabular}

Table 3: Revenue and production costs (TND/ha)

\begin{tabular}{lrrrr}
\hline & 2007 & \multicolumn{1}{c}{2008} & 2009 & Average \\
\hline Revenue & 1070.00 & 823.00 & 1088.00 & 993.00 \\
Revenue of the olive trees & 888.00 & 603.00 & 816.00 & 769.00 \\
Revenue of the crops & 1449.00 & 1266.00 & 1567.00 & 1427.00 \\
Total production costs & 723.00 & 608.00 & 712.00 & 681.00 \\
Irrigation costs (\%) & 43.29 & 46.48 & 44.55 & 44.77 \\
Mechanization costs (\%) & 17.60 & 17.26 & 16.68 & 17.18 \\
Fertilization costs (\%) & 8.40 & 10.38 & 9.71 & 9.49 \\
Hired labor (\%) & 15.78 & 14.31 & 15.11 & 15.07 \\
Others (\%) & 14.91 & 11.55 & 13.94 & 13.00 \\
\hline
\end{tabular}

Table 4: Descriptive statistics of DEA variables

\begin{tabular}{llrrrr}
\hline 2007 & Farms & \multicolumn{1}{c}{ Mean } & \multicolumn{1}{c}{ Min } & \multicolumn{1}{l}{ Max } & \multicolumn{1}{c}{ S.D } \\
\hline Oliv & 47 & 3710.00 & 0.00 & 16700.00 & 3481.00 \\
Cult & 47 & 2910.00 & 0.00 & 14160.00 & 3411.00 \\
Land & 47 & 4.67 & 0.25 & 16.00 & 3.72 \\
Water & 47 & 12615.00 & 810.00 & 48476.00 & 10691.00 \\
Mecan & 47 & 569.00 & 20.00 & 2300.00 & 569.00 \\
Fertil & 47 & 330.00 & 0.00 & 1676.00 & 330.00 \\
Lab & 47 & 723.00 & 0.00 & 4541.00 & 723.00 \\
2008 & & & & & \\
Oliv & 47 & 2499.00 & 0.00 & 9000.00 & 2144.00 \\
Cult & 47 & 2605.00 & 0.00 & 15680.00 & 3568.00 \\
Land & 47 & 4.69 & 0.25 & 16.00 & 3.68 \\
Water & 47 & 9939.00 & 427.00 & 23255.00 & 6535.00 \\
Mecan & 47 & 508.00 & 240.00 & 1820.00 & 428.00 \\
Fertil & 47 & 371.00 & 0.00 & 1559.00 & 405.00 \\
Lab & 47 & 654.00 & 0.00 & 3195.00 & 875.00 \\
2009 & & & & & \\
Oliv & 47 & 3331.00 & 0.00 & 12180.00 & 3061.00 \\
Cult & 47 & 3641.00 & 0.00 & 20800.00 & 4847.00 \\
Land & 47 & 4.63 & 0.25 & 16.00 & 3.62 \\
Water & 47 & 12262.00 & 0.00 & 50328.00 & 11130.00 \\
Mecan & 47 & 523.00 & 34.00 & 2160.00 & 504.00 \\
Fertil & 47 & 382.00 & 0.00 & 1470.00 & 391.00 \\
Lab & 47 & 695.00 & 0.00 & 3650.00 & 874.00 \\
\hline
\end{tabular}

Table 4 presents summary statistics of these variable.

In order to compute the technical efficiency and the water use efficiency we have solved respectively the linear programs (1) and (2) using General Algebraic Modelling System software (GAMS).
Table 5: Statistics of the efficiency scores

\begin{tabular}{|c|c|c|c|}
\hline & 2007 & 2008 & 2009 \\
\hline \multicolumn{4}{|c|}{ CRS Technical efficiency average 0.72} \\
\hline Mean & 0.75 & 0.73 & 0.69 \\
\hline Min & 0.00 & 0.21 & 0.00 \\
\hline Max & 1.00 & 1.00 & 1.00 \\
\hline SD & 0.29 & 0.27 & 0.31 \\
\hline Farms* & 18.0 & 19.0 & 17.0 \\
\hline \multicolumn{4}{|c|}{ VRS Technical efficiency average 0.81} \\
\hline Mean & 0.86 & 0.78 & 0.78 \\
\hline Min & 0.27 & 0.24 & 0.09 \\
\hline Max & 1.00 & 1.00 & 1.00 \\
\hline $\mathrm{SD}$ & 0.22 & 0.25 & 0.26 \\
\hline Farms* & 28.0 & 24.0 & 23.0 \\
\hline \multicolumn{4}{|c|}{ SE Scale efficiency average 0.88} \\
\hline Mean & 0.86 & 0.92 & 0.87 \\
\hline Min & 0.00 & 0.37 & 0.00 \\
\hline Max & 1.00 & 1.00 & 1.00 \\
\hline $\mathrm{SD}$ & 0.22 & 0.12 & 0.23 \\
\hline Farms* & 18.0 & 19.0 & 18.0 \\
\hline \multicolumn{4}{|c|}{ WUE Water Use Efficiency average 0.68} \\
\hline Mean & 0.81 & 0.65 & 0.59 \\
\hline Min & 0.13 & 0.09 & 0.00 \\
\hline Max & 1.00 & 1.00 & 1.00 \\
\hline SD & 0.28 & 0.37 & 0.41 \\
\hline Farms* & 28.0 & 24.0 & 22.0 \\
\hline
\end{tabular}

*: Number of farms perfectly efficient

Regarding the performance of the production system, our empirical findings revealed that around $50 \%$ of the farmers used the inputs inefficiently (Table $5)$. Indeed, the averages of the technical efficiency under CRS and VRS were assessed respectively at 0.72 and 0.81 . However, we have to highlight the decrease of the technical efficiency which passed from 0.75-0.69 under the CRS and from 0.86-0.78 under the VRS. Hence the scale efficiency reached an average of 0.88 . Only three farmers were operating at the optimal scale over the three harvesting years.

Regarding the use of the irrigation water, the empirical findings revealed an average of the water use efficiency lower than the technical efficiency reaching 0.68. In order to investigate the actual weight of the irrigation water in the technology process, we have analyzed the Spearman correlation statistic between the technical efficiency and the water use efficiency (Table 6). The result has shown strongly dependence which is significant at $1 \%$. 
Am. J. Environ. Sci., 8 (3): 241-247, 2012

Table 6: Spearman's Test

\begin{tabular}{|c|c|c|c|c|}
\hline \multirow{2}{*}{\multicolumn{2}{|c|}{ Technical efficiency }} & \multicolumn{3}{|c|}{ Water Use efficiency } \\
\hline & & 2007 & 2008 & 2009 \\
\hline \multirow[t]{2}{*}{2007} & CRS & $0.767 * * *$ & & \\
\hline & VRS & $0.989 * * *$ & & \\
\hline \multirow[t]{2}{*}{2008} & CRS & & $0.876 * * *$ & \\
\hline & VRS & & $0.933 * * *$ & \\
\hline \multirow[t]{2}{*}{2009} & CRS & & & $0.833 * * *$ \\
\hline & VRS & & & $0.864 * * *$ \\
\hline
\end{tabular}

\section{DISCUSSION}

Given the exiguity of the irriagble areas farmers practiced intercalated cropping system in order to diversify their production and to meet their needs as well as those of their breeding animals. Hence farmers attempt to intensify the land use. However, the irrigated areas did not really change over the three harvesting years because of the weakness of the financial capability and the water constraints.

Farmers cultivated cereal crops (barley and wheat), forage crops and horticulture crops. The main result showed that farmers concentrated the horticulture crops in the IPRAs where they had more freedom to manage their irrigation scheme. In fact the irrigated area of those crops was 3-10 times of that in the IPBAs.

Although the dominance of the floodwater which caused a high level of water wasting, the water consumption remains lower than the standard target projected by the water authorities $(6000-7000 \mathrm{~m} 3 / \mathrm{ha})$. Hence farmers practice complimentary irrigation and the rainfall level may affect the production. Therefore the variability of the revenue might straightforwardly explained by the variability of the rainfall (Fig. 3). In fact in 2008 the region had received only $50 \%$ of the rainfall average and unfortunately the water consumption has decreased. According to the water resource, the IPBAs appear more productive than the IPRAs. The charges of production did not show important changes over the surveyed harvesting years.

The results of the technical efficiency scores suggest that farmers might improve their capability of the technology management process allowing them to save up to $19 \%$ of the inputs currently used. According to the results of Chemak et al. (2010) the technical inefficiency of the inputs uses was confirmed. Within this context, Speelman et al. (2008) found out the average overall technical efficiencies for the CRS and VRS are 0.51 and 0.84 , respectively indicating that substantial inefficiencies occurred in farming operations of the sample farm households using irrigation in North-West province of South Africa. Our results is also consistent with a recent meta-analysis by
Bravo-Ureta et al. (2007) where they showed that in less developed countries, mean values of technical efficiency par study averaged about 0.74 . On the other hand, farmers appear operating closer the optimal scale.

One third of the irrigation water currently used is judged as an overconsumption. This may due to many factors such as the decayed channels, the irrigation system and the ability of farmers in terms of the irrigation piloting. Hence, the irrigation management plays the paramount role in the technology process and farmers should improve their practices and adjust adequately their needs to save more water.

\section{CONCLUSION}

This study has analyzed the overall technical efficiency and the water use efficiency of the irrigated farms in the Sidi Bouzid region over three harvesting years 2007, 2008 and 2009 using the DEA model. The results showed that the inputs use in the sample farm households was in a state of inefficient productive allocation. The irrigation water use revealed an over consumption estimated at one third of the available water currently used. This water irrigation inefficiency is strongly correlated to the technical inefficiency and therefore the irrigation management is likely to be the main factor of the technology process. Also, the results revealed the decrease of the technical efficiency and the water use efficiency over the three harvesting years. These results should be deeply investigated to find out the main factor of this deterioration.

Given these empirical findings, the challenge of reconciliation between production targets and saving irrigation water appears affordable. In fact the state intervention should involve two strategies. The first one encompasses the improvement of the farmers' capability as the main factor of saving water at the field level. Within this context an operational farmers' capacity building program seems very useful to sensitise them about the relationship between water saving and profitability in order to encourage farmers to participate in irrigation management. Additional research on allocative and economic efficiency would confirm this linkage. The second strategy should takes into account the extent weight of saving irrigation water for implementing the policy of the water management demand. According to our results, by saving $32 \%$ of the irrigation water, currently used, one might alleviate water scarcity. Therefore, in order to generalize this suggestion it will be useful to extend this research by analyzing more irrigated areas of other regions. However, the government has to provide financial support and technical assistance in order to encourage 
farmers to optimize the management of their irrigation system and to adjust their technologies towards the optimal scale. Moreover, the extension facilities should be enhanced in order to develop suitable options helping farmers achieving the optimal water use efficiency and coping with the water scarcity.

\section{REFERENCES}

Abaab, A., 1999. Agricultural modernization and its effects on agricultural production systems: The case of Sidi Bouzid region in central Tunisia. University of Gent, Belgium.

Banker, R.D., A. Charnes and W.W. Cooper, 1984. Some models for estimating technical and scale inefficiencies in data envelopment analysis. Manage. Sci., 30: 1078-1092.

Bravo-Ureta, B.E., D. Solis, V.H.M. Lopez, J.F. Mripani and A. Thiam et al., 2007. Technical efficiency in farming: A meta-regression analysis. J. Produ. Anal., 27: 57-72. DOI: 10.1007/s11123006-0025-3

Charnes, A., W.W. Cooper and E. Rhodes, 1978. Measuring the efficiency of Decision Making Units. Eur. J. Operat. Res., 2: 429-444. DOI: 10.1016/0377-2217(78)90138-8

Chemak, F., J.P. Boussemart and F. Jacquet, 2010. Farming system performance and water use efficiency in the Tunisian semi-arid region: Data envelopment analysis approach. Int. Trans. Operat. Res., 17: 381-396. DOI: 10.1111/j.14753995.2009.00736.x

Chraga, G. and F. Chemak, 2003. The collective interest groups, a strategic tool for participatory management of water resources in case of ICG Mahdia. Proceedings of the 20th Europeen Conference of ICID Montpellier, (ICIDM' 03), France.

Cook, W.D. and L.M. Seiford, 2009. Data Envelopment Analysis (DEA)- Thirty on. Eur. J. Operat. Res., 192: 1-17. DOI: 10.1016/j.ejor.2008.01.032

Emrouznejad, A., B.R. Parker and G. Tavares, 2008. Evaluation of research in efficiency A survey analysis of the first 30 years of scholarly literature in DEA. J. Socio-Econ. Plann. Sci., 42: 151-157. DOI: 10.1016/j.seps.2007.07.002

Fare, R., S. Grosskopf and C.A.K. Lovell, 1994. Production Frontiers. 1st Edn., Cambridge University Press, Cambridge, ISBN: 0521420334, pp: 296.
Farrell, M.J., 1957. The measurement of productive efficiency. J. Royal Stat. Soc., 120: 253-290.

Farzianpour, F., S. Hosseini, T. Amali, S. Hosseini and S.S. Hosseini, 2012. The Evaluation of relative efficiency of teaching hospitals. Am. J. Applied Sci., 9: 392-398. DOI: 10.3844/ajassp.2012.392.398

Gorton, M. and S. Davidova, 2004. Farm productivity and efficiency in the CEE applicant countries: A synthesis of results. Agric. Econ., 30: 1-16. DOI: 10.1016/j.agecon.2002.09.002

Hemdane, A., 2002. L'irrigation en Tunisie. Ministry of Agriculture (DGGR), Tunisia.

Karagiannis, G., V. Tzouvelekas and A. Xepapadeas, 2003. Measuring irrigation water efficiency with a stochastic production frontier: An application to Greek out-of-season vegetable cultivation. Environ. Resource Econ., 26: 57-72. DOI: 10.1023/A:1025625402762

Odeck, J., 2009. Statistical precision of DEA and Malmquist indices: A bootstrap application to Norwegian grain producers. Omega, 37: 10071017. DOI: 10.1016/j.omega.2008.11.003

Omezzine, A. and L. Zaibet, 1998. Management of modern irrigation systems in Oman: Allocative vs. irrigation efficiency. Agric. Water Manage., 37: 99-107. DOI: 10.1016/S0378-3774(98)00045-6

Rayeni, M.M. and F.H. Saljooghi, 2010. Benchmarking in the academic departements using data envelopement analysis. Am. J. Applied Sci., 7: 1464-1469. DOI: 10.3844/ajassp.2010.1464.1469

Shideed, K., 2005. Assessing On-farm Water-use Efficiency: A New Approach Methodology and Six Ase Studies. 1st Edn., ICARDA, Aleppo, Syria, pp: 86.

Speelman, S., M. D’Haese, J. Buysse, L. D’Haese, 2008. A measure for the efficiency of water use and its determinants, a case study of small-scale irrigation schemes in North-West Province, South Afr. Agric. Syst., 98: 31-39. DOI: 10.1016/j.agsy.2008.03.006

Wang, X.Y., 2010. Irrigation Water Use Efficiency of farmers and its determinants: Evidence from survey in Northwestern China. Agric. Sci. China, 9: 1326-1337. DOI: $10.1016 / \mathrm{S} 1671-$ 2927(09)60223-6

Zreika, M. and N. Elkanj, 2011. Banking efficiency in Lebanon: An empirical investigation. J. Soc. Sci., 7: 199-208. DOI: 10.3844/jssp.2011.199.208 